\title{
The effect of resistance exercise direction for hip joint stabilization on lateral abdominal muscle thickness
}

\author{
Ju-Hyeon Jung', Sang-Yeol Lee ${ }^{2, *}$ \\ 'Department of Physical Therapy, Gimhae College, Gimhae, Korea \\ 2Department of Physical Therapy, College of Science, Kyungsung University, Busan, Korea
}

The aim of this study was to determine the effects of resistance direction in hip joint stabilization exercise on change in lateral abdominal muscle thickness in healthy adults. Twenty-six healthy adults were randomly allocated to either a hip stabilization exercise by hip straight resistance group $(n=12)$ or a hip diagonal resistance group $(n=14)$. The outcome measures included contraction thickness ratio in transversus abdominis (TrA), internal oblique (IO) and external oblique, and TrA lateral slide were assessed during the abdominal drawing-in maneuver by b-mode ultrasound. The researcher measured the abdominal muscle thickness of each participant before the therapist began the intervention and at the moment intervention was applied. There was a signifi- cant difference in lateral abdominal muscle thickness between the straight resistance exercise of hip joint group and the diagonal resistance exercise of hip joint group. Significant differences were found between the two groups in the percentage of change of muscle thickness of the $\operatorname{Tr} A(P=0.018)$ and in the thickness ratio of the $\operatorname{Tr} A(P=0.018)$. Stability exercise accompanied by diagonal resistance on the hip joint that was applied in this study can induce automatic contraction of the 10 and $\operatorname{Tr} A$, which provides stability to the lumbar spine.

Keywords: Stabilization exercise, Hip stabilization, Resistance direction, Lateral abdominal muscle thickness

\section{INTRODUCTION}

Spine stability starts from the point at which the nervous system receives movement and position information from the proprioceptors located in joints, muscles, and ligaments. The nervous system determines location control, movement, and the activation of the muscle system and executes spine balance by harmonizing and integrating nerves, skeletal structure, ligaments, and muscle structure (Panjabi, 1992). There exist two muscle systems in the human body that maintain spine stability. The global muscle system includes the rectus abdominis, external obliques (EOs), and iliocostalis, which are not directly attached to the spine but execute large force by acting on the body trunk. These muscles provide stability to the trunk but cannot directly affect spine segments. The local muscle system includes the transversus abdominis ( $\operatorname{Tr} A)$, internal obliques (IOs), posterior fiber, and multifidus and directly controls the spinal segments, to which it is directly attached and provides stability (Bergmark, 1989).

Stevens et al. (2006) argued that overall harmony and coordination of the trunk muscles, rather than activation of a specific muscle, are important for spine stability. Their study reported that adjusted co-operation between global muscles and local muscles maintains a stabilized spinal state (Marshall and Murphy, 2005; Stevens et al., 2007).

Recently, a number of studies have attempted to increase trunk stability and reduce pain through activation of local muscles by inducing exact co-contraction of the deep trunk muscles the $\operatorname{Tr} A$ and multifidus and reducing usage of the global muscle system using exercise programs focused on spine segment stability (Park, 2010; Rackwitz et al., 2006; van Middelkoop et al., 2011).

Meanwhile, suboptimal pelvic joint stability can cause lumbopelvic pain and hamstring pain (Arumugam et al., 2012). Poor endurance and delayed firing of the hip extensor and abductor muscles can cause low back pain and lower extremity instability
${ }^{\star}$ Corresponding author: Sang-Yeol Lee (D) http://orcid.org/0000-0003-4428-9101 Department of Physical Therapy, College of Science, Kyungsung University, 309, Suyeong-ro, Nam-gu, Busan 48434, Korea

Tel: +82-51-663-4873, Fax: +82-51-628-4870, E-mail: sjslh486@hanmail.net

Received: June 8, 2016 / Accepted: September 27, 2016
This is an Open Access article distributed under the terms of the Creative Commons Attribution Non-Commercial License (http://creativecommons.org/licenses/by-nc/4.0/) which permits unrestricted non-commercial use, distribution, and reproduction in any medium, provided the original work is properly cited. 


\section{(Nadler et al., 2002).}

To address these problems, recent studies have applied interventions that provide stability to the hip joint (Park et al., 2010). The application of these intervention methods is based on a socalled "self-locking mechanism," through which form closure, force closure, and neuromuscular control of the surrounding muscle structure are reinforced to assist the stability of the sacroiliac joint (Arumugam et al., 2012).

However, few studies verify the effect of intervention for hip joint stability on trunk stability according to the application method. Therefore, this study attempts to corroborate the impact on the change of lateral abdominal muscle thickness that contributes to lumbar stability according to the resistance direction when applying interventions for hip joint stability.

\section{MATERIALS AND METHODS}

\section{Participants}

The purpose and process of the study were explained to the participants, who voluntarily agreed to participate in the study. With regard to selecting healthy participants for this study, only those who had not experienced low back pain in the previous 6 months, did not have a neurologic disease, and had not received surgical intervention were selected (Yang and Park, 2014).

\section{Design}

Twenty-six healthy adults were randomly assigned to one of two groups: (a) The straight resistance exercise of hip joint (SR) group received hip stabilization exercise by hip straight resistance, and (b) the diagonal resistance exercise of hip joint (DR) group received hip stabilization exercise by hip diagonal resistance.

The researcher measured the abdominal muscle thickness of each participant before the therapist began the intervention and at the moment intervention was applied. A therapist with more than 10 years of professional experience implemented the hip stability

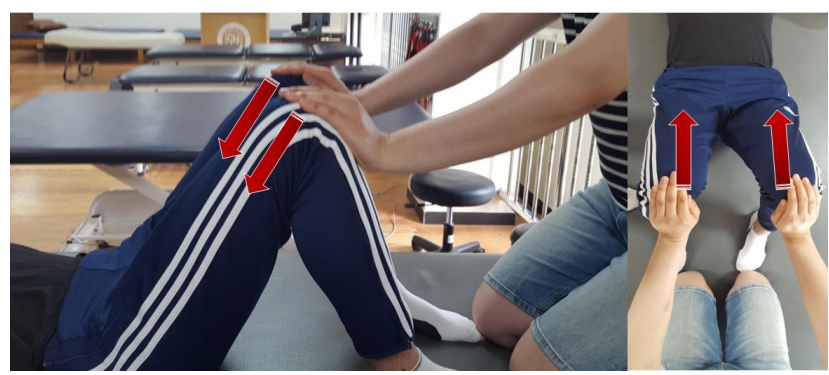

Fig. 1. Hip stabilization exercise by hip straight resistance. exercise with the subjects.

\section{Exercise program \\ Hip stabilization exercise by hip straight resistance}

While the subjects were in the supine position with the hip joint and knee joint in $90^{\circ}$ of flexion, the therapist put pressure straight from the lower femur and upper leg right above the knee joint in both legs toward the femur head. Pressure resistance of a magnitude at which minute abdomen tension could be felt was permitted. The therapist kept his hand, which provided resistance, at a constant location during the intervention, and the subjects sustained resistance to the therapist's resistance when motion was observed (Ishida et al., 2012) (Fig. 1).

\section{Hip stabilization exercise by hip diagonal resistance}

The subjects maintained the same posture as that during the previous hip stabilization exercise. The therapist applied pressure diagonally from the lower femur and upper leg right above the knee joint in both legs toward the femur head of the hip joint at the opposite side to the therapist. Pressure resistance of a magnitude at which minute abdomen tension could be felt was permitted. The therapist kept his hand, which provided resistance, at a constant location during the dynamic exercise, and the subjects sustained resistance against the therapist's resistance when motion was observed (Ishida et al., 2012) (Fig. 2).

\section{Measurements}

\section{Ultrasound measurement of lateral abdominal muscle thickness}

An ultrasound device (Esaote Benelux B.V., Maastricht, The Netherlands) was used to measure the abdominal muscle thickness. The tester located the linear probe $(7.5 \mathrm{MHz})$ at the middle of the eleventh costal cartilage and iliac crest to obtain a standardized ultrasonography image and measured the abdominal muscle on the dominant side of the subjects, as was checked in advance (Park, 2010; Teyhen et al., 2007). The space where the TrA and

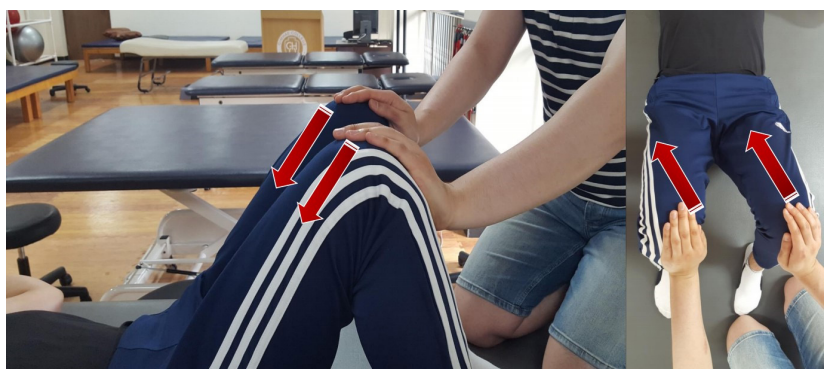

Fig. 2. Hip stabilization exercise by hip diagonal resistance. 

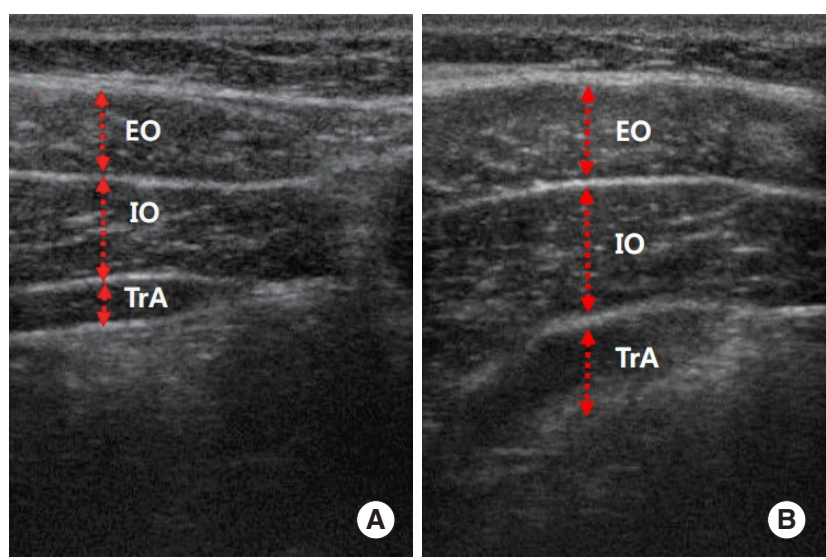

Fig. 3. Ultrasound measurement of the abdominal muscles thickness. Thickness measurement were obtained at rest $(A)$ and full contraction $(B)$ during intervention. EO, external oblique; IO, internal oblique; TrA, transversus abdominis.

thoracolumbar fascia meet was displayed on the right side of the ultrasonography image (Springer et al., 2006; Teyhen et al., 2007). To minimize error in the change in thickness of the abdominal muscle, which can be caused by respiration, all ultrasonography images was collected at the end point of expiration (Fig. 3). The thickness of each abdominal muscle was measured 3 times to compute the average. The percentage of changes from resting expiration were calculated as [(maximum expiration-resting expiration)/resting expiration $\times 100$ ] (\%) for the measurement of $\operatorname{Tr} A$ and IO muscle thickness during both interventions (Ishida et al., 2012), Contraction thickness ratio (TR) was calculated by dividing muscle thickness at maximal contraction by muscle thickness at rest (Vasseljen and Fladmark, 2010).

\section{Statistical analysis}

Data obtained from the two groups of subjects were analyzed using IBM SPSS ver. 18.0 (IBM Co., Armonk, NY, USA). Between-group comparisons were performed using the Mann-Whitney $U$-test. The level of statistical significance was set to 0.05 .

\section{RESULTS}

The mean values and standard deviation (SD) of physical characteristics (age, height, weight) of all 26 participants in the SR group and DR group are shown in Table 1 . Statistically significant differences were not found between the two groups, as shown in Table 1 .

\section{Measurement of lateral abdominal muscle thickness}

The mean values, $\mathrm{SD}$, percentage of change of muscle thickness
Table 1. Characteristics of study participants $(n=26)$

\begin{tabular}{lcc}
\hline Characteristic & SR Group $(n=12)$ & DR Group $(n=14)$ \\
\hline Gender, male:female & $6: 6$ & $8: 6$ \\
Age $(\mathrm{yr})$ & $24.16 \pm 3.06$ & $24.14 \pm 2.82$ \\
Height $(\mathrm{cm})$ & $168.50 \pm 9.59$ & $169.42 \pm 9.14$ \\
Weight $(\mathrm{kg})$ & $61.25 \pm 11.91$ & $61.71 \pm 11.23$ \\
\hline
\end{tabular}

Values are presented as mean \pm standard deviation.

SR, straight resistance exercise of hip joint; DR, diagonal resistance exercise of hip joint.

Table 2. Comparison of pulmonary function and PCMT, TR of the SR and DR groups

\begin{tabular}{lrrrc}
\hline Variable & SR group & DR group & Z & P-value \\
\hline PCMT & & & & \\
EO $(\%)$ & $-4.68 \pm 14.00$ & $-10.59 \pm 20.16$ & -1.132 & 0.258 \\
IO $\%)$ & $21.67 \pm 13.71$ & $28.42 \pm 32.19$ & -1.234 & 0.217 \\
TrA $(\%)$ & $21.89 \pm 16.78$ & $43.20 \pm 26.97$ & -2.366 & 0.018 \\
TR & & & & \\
EO (\%) & $0.95 \pm 0.14$ & $0.89 \pm 0.20$ & -1.132 & 0.258 \\
IO (\%) & $1.21 \pm 0.13$ & $1.28 \pm 0.32$ & -1.234 & 0.217 \\
TrA $(\%)$ & $1.21 \pm 0.16$ & $1.43 \pm 0.26$ & -2.366 & 0.018 \\
\hline
\end{tabular}

Values are presented as mean \pm standard deviation.

PCMT, percentage of change of muscle thickness; TR, thickness ratio of lateral abdominal muscles; SR, straight resistance exercise of hip joint; DR, diagonal resistance exercise of hip joint; EO, external oblique; I0, internal oblique; TrA, transversus abdominis.

(PCMT), and TR of the lateral abdominal muscles during intervention for both groups are shown in Table 2. Significant differences were found between the two groups in the PCMT of the $\operatorname{TrA}(P=0.018)$ and in the TR of the $\operatorname{Tr} A(P=0.018)$.

\section{DISCUSSION}

The enhancement of the dynamic stability of the deep core muscles is critical during functional movements for the stability of the sacroiliac joint, through which load is appropriately delivered to the lower limbs (Park et al., 2010).

Contraction of the $\operatorname{Tr} A$ significantly decreases the laxity of the sacroiliac joint. This decrease in laxity is larger than that caused by a bracing action using all the lateral abdominal muscles (Hoek van Dijke et al., 1999). These results support the argument that $\operatorname{Tr} A$ contractions should be used to treat low back pain (Neumann, 2013). It also implies close correlation among the lateral abdominal muscles, sacroiliac joint, and hip joint. This study examined the impact of hip joint pressure resistance during hip joint stabilization exercises used in clinics on the lateral abdominal muscles. For this purpose, the study investigated the anatomi- 
cal structure and mechanism pressure resistance direction that affect the change of abdominal muscle thickness.

The study results proved that hip joint stabilization exercise increased PCMT and TR value, which represents the contractile force of the $\operatorname{Tr} A$ and IO among the lateral abdominal muscles. The study confirmed that resistance in a diagonal direction can contract $\operatorname{Tr} A$ thickness more efficiently. These results can be contributed to the simultaneous action of the ligaments of the sacroiliac joint, $\operatorname{Tr} \mathrm{A}$, and IO as the therapist applied approximation resistance of the hip joint to allow the ilium to put pressure on the sacrum.

Previous studies reported that the proper participation of the overall spinal muscles, rather than when one trunk muscle makes the largest contribution under different loading conditions, is important for spine stability. It has been reported that motor control training based on the participation of all spinal muscles under diverse spine-loading conditions is required for rehabilitation exercises to enhance spine stability (Teyhen et al., 2007).

The hip joint stabilization exercise applied in this study induced the cocontraction of the trunk muscles by contracting muscles located in the pelvic region, and this could increase lumbar spine stability.

Meanwhile, Adler et al. (2008) argued that applying pressure in a diagonal direction can indirectly activate more muscles in a broad part and that the contribution of muscles involved in spine stability changes according to the loading magnitude and direction (Teyhen et al., 2007). The results of this study were consistent with those of previous studies as resistance of the hip joint in a diagonal direction caused significant contraction of the TrA. Here, pressure on the iliac crest was created along with the cocontraction of muscles surrounding the femur when applying hip joint pressure resistance diagonally. As a result, the subject made an isometric contraction by using the hip extensor muscle to overcome resistance when the therapist applied pressure, which resulted in a phenomenon in which the femur head was fixated on the acetabular fossa of the ilium. Moreover, the gluteus maximus and medius muscles of the hip joint that were closer to the therapist were further activated when applying diagonal resistance, and the femur head was firmly fixated inward to the acetabular fossa (Neumann, 2013). As for the hip joint at the opposite side to the therapist, the ilium was pulled toward the spine along with the contraction of the $\operatorname{Tr} A$, which was suspended at the iliac crest by contracting the adductor muscle. Activation of the $\operatorname{Tr} A$ was confirmed based on the theoretical background, according to which the neighboring ligaments of the $\operatorname{Tr} A$ and sacroiliac (SI) joint act together to lower SI joint laxity and provide spine stability (Hoek van Dijke et al., 1999; Neumann, 2013).

Kwon et al. (2011) argued that inducing selective contraction of the $\operatorname{Tr} \mathrm{A}$ under the condition of removing the activity of the EO muscle is very difficult. Arguing that there are still difficulties in applying intervention based on selectively contracting the $\operatorname{Tr} A$, such as abdominal hollowing exercise, the study applied visual feedback. However, intervention using visual feedback is restrictively applied to patients in clinics due to problems in the therapy room environment and therapists' technical limitations. Moreover, the focus of interest has recently been moving to the automatic activity of muscles during different actions, while previous studies conventionally focused on the voluntary activation of the deep abdominal muscles (Rasouli et al., 2011). Therefore, stability exercise accompanied by diagonal resistance on the hip joint that was applied in this study can induce automatic contraction of the IO and $\operatorname{Tr} A$, which provides stability to the lumbar spine. We believe that this is a more efficient intervention method than the existing stability exercise programs that require special and precise technology.

\section{CONFLICT OF INTEREST}

No potential conflict of interest relevant to this article was reported.

\section{REFERENCES}

Adler SS, Beckers D, Buck M. PNF in practice: an illustrated guide. Heidelberg: Springer; 2008.

Arumugam A, Milosavljevic S, Woodley S, Sole G. Effects of external pelvic compression on form closure, force closure, and neuromotor control of the lumbopelvic spine: a systematic review. Man Ther 2012; 17:275-284.

Bergmark A. Stability of the lumbar spine; a study in mechanical engineering. Acta Orthop Scand Suppl 1989;230:1-54.

Hoek van Dijke GA, Snijders CJ, Stoeckart R, Stam HJ. A biomechanical model on muscle forces in the transfer of spinal load to the pelvis and legs. J Biomech 1999;32:927-933.

Ishida $\mathrm{H}$, Hirose R, Watanabe $\mathrm{S}$. Comparison of changes in the contraction of the lateral abdominal muscles between the abdominal drawing-in maneuver and breathe held at the maximum expiratory level. Man Ther 2012;17:427-431.

Kwon NH, Lee HO, Park DJ. The use of real-time ultrasound imaging for feedback during abdominal hollowing. J Korean Soc Phys Med 2011; 6:303-310.

Marshall PW, Murphy BA. Core stability exercises on and off a Swiss ball. 
Arch Phys Med Rehabil 2005;86:242-249.

Nadler SF, Malanga GA, Bartoli LA, Feinberg JH, Prybicien M, Deprince M. Hip muscle imbalance and low back pain in athletes: influence of core strengthening. Med Sci Sports Exerc 2002;34:9-16.

Neumann DA. Kinesiology of the musculoskeletal system: foundations for rehabilitation. St. Louis (MO): Elsevier Health Sciences; 2013.

Panjabi MM. The stabilizing system of the spine. Part I. Function, dysfunction, adaptation, and enhancement. J Spinal Disord 1992;5:383-389.

Park DJ. The effect of real-time ultrasound imaging feedback during abdominal hollowing in four point kneeling to healthy men. J Korean Soc Phys Thera 2010;22:1-6.

Park KM, Kim SY, Oh DW. Effects of the pelvic compression belt on gluteus medius, quadratus lumborum, and lumbar multifidus activities during side-lying hip abduction. J Electromyogr Kinesiol 2010;20: 1141-1145.

Rackwitz B, de Bie R, Limm H, von Garnier K, Ewert T, Stucki G. Segmental stabilizing exercises and low back pain. What is the evidence? A systematic review of randomized controlled trials. Clin Rehabil 2006;20:553-567.

Rasouli O, Arab AM, Amiri M, Jaberzadeh S. Ultrasound measurement of deep abdominal muscle activity in sitting positions with different stability levels in subjects with and without chronic low back pain. Man Ther 2011;16:388-393.

Springer BA, Mielcarek BJ, Nesfield TK, Teyhen DS. Relationships among lateral abdominal muscles, gender, body mass index, and hand dominance. J Orthop Sports Phys Ther 2006;36:289-297.

Stevens VK, Bouche KG, Mahieu NN, Coorevits PL, Vanderstraeten GG, Danneels LA. Trunk muscle activity in healthy subjects during bridging stabilization exercises. BMC Musculoskelet Disord 2006;7:75.

Stevens VK, Coorevits PL, Bouche KG, Mahieu NN, Vanderstraeten GG, Danneels LA. The influence of specific training on trunk muscle recruitment patterns in healthy subjects during stabilization exercises. Man Ther 2007;12:271-279.

Teyhen DS, Gill NW, Whittaker JL, Henry SM, Hides JA, Hodges P. Rehabilitative ultrasound imaging of the abdominal muscles. J Orthop Sports Phys Ther 2007;37:450-466.

van Middelkoop M, Rubinstein SM, Kuijpers T, Verhagen AP, Ostelo R, Koes BW, van Tulder MW. A systematic review on the effectiveness of physical and rehabilitation interventions for chronic non-specific low back pain. Eur Spine J 2011;20:19-39.

Vasseljen O, Fladmark AM. Abdominal muscle contraction thickness and function after specific and general exercises: a randomized controlled trial in chronic low back pain patients. Man Ther 2010;15:482-489.

Yang KH, Park DJ. Reliability of ultrasound in combination with surface electromyogram for evaluating the activity of abdominal muscles in individuals with and without low back pain. J Exerc Rehabil 2014; 10:230-235. 